\title{
EEN LIGGENDE STIER
}

De stier is in India vanouds verbonden met de god Shiva. Op oude munten en zegels werd hij wel afgebeeld als verschijning van de god. Later werd hij vooral als Shiva's rijdier aangeduid en werd Shiva ook staande op de stier afgebeeld.

Vooral in Zuid-India ruimde men dan ook bij de opzet van een tempel voor Shiva een passende plaats voor hem in. Het hoofdbeeld van Shiva, of zijn symbool, de lingga, werd ondergebracht in het eigenlijke heiligdom (garbhagrha). Voor de stier werd meestal een voor de ingang gelegen paviljoen gebouwd. Vanaf die plaats kon hij door de deuropening van het hoofdheiligdom steeds het beeld van zijn meester in de gaten houden (afb. 1).

Onze stier ${ }^{1}$ (afb. 2 ) is jong en zijn hoorns zijn nog niet volgroeid. Hij heeft de achterpoten naar rechts onder zich gelegd, zodat de onderkant van de hoef van zijn linkerachterpoot aan de rechterkant zichtbaar is. Zijn staart heeft hij ook naar rechts gelegd; het uiteinde ligt over zijn rechterpoot. Zijn rechtervoorpoot ligt gevouwen, maar de linker staat startklaar met zijn hoef op de grond. Hoewel hij ligt te rusten heft hij de kop fier omhoog en heeft hij de blik vooruit gericht. Bij het minste of geringste teken kan hij in actie komen. Hij likt met zijn tong in zijn neusgaten.

Dat hij niet de eerste de beste stier is, is af te leiden uit het kleed en de sieraden die hij draagt. Op zijn rug is een rijk geborduurd dekkleed gelegd, dat met een band onder zijn lijf is vastgeknoopt. Een serie van vier halsbanden is om zijn nek gehangen. Van boven naar beneden zijn het:

1. een koord met een rozet, die precies in het midden valt;

2. een koord waaraan ronde rinkelbelletjes (ghurghura) hangen;

3. een koord met klokjes (ghantika) afgewisseld met kwasten en als laatste

Afteelding 1

Overlangs doorsnede van een Shivatempel uit de Cola periode. Van links naar rechts: het toegangsgebouwtje, de liggende stier (hier in de openlucht), de ingang, de zuilenzaal, de vestibule en dan het heiligdom zelf met een omlooppad Uit: |.C. Harle, The Art and Architecture of the Indian Subcontinent, Harmondsworth en New York, 1986, p. 315

\section{4. een koord met een kwast.}

Deze vier koorden lijken op de rug boven de bult aan elkaar geknoopt.

Op zijn voorhoofd ligt een rozet, waaraan drie parelstrengen hangen. Het is met koordjes aan zijn hoorns bevestigd.

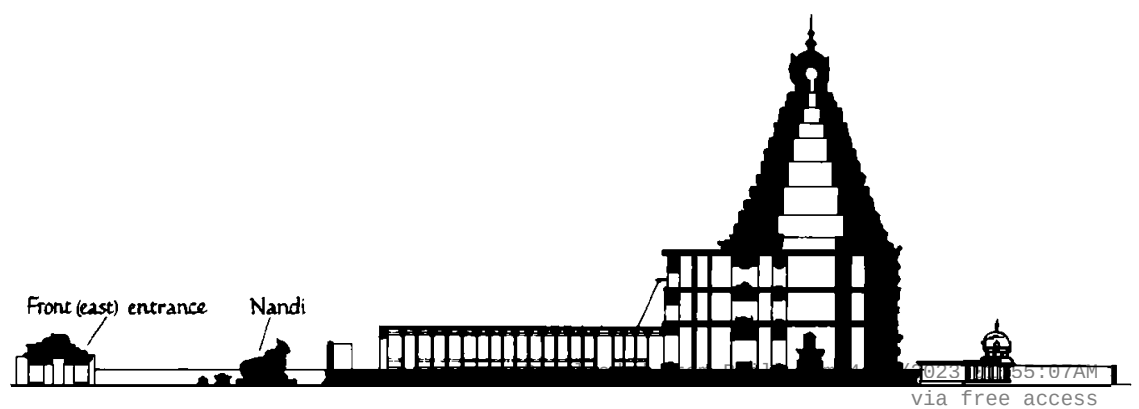




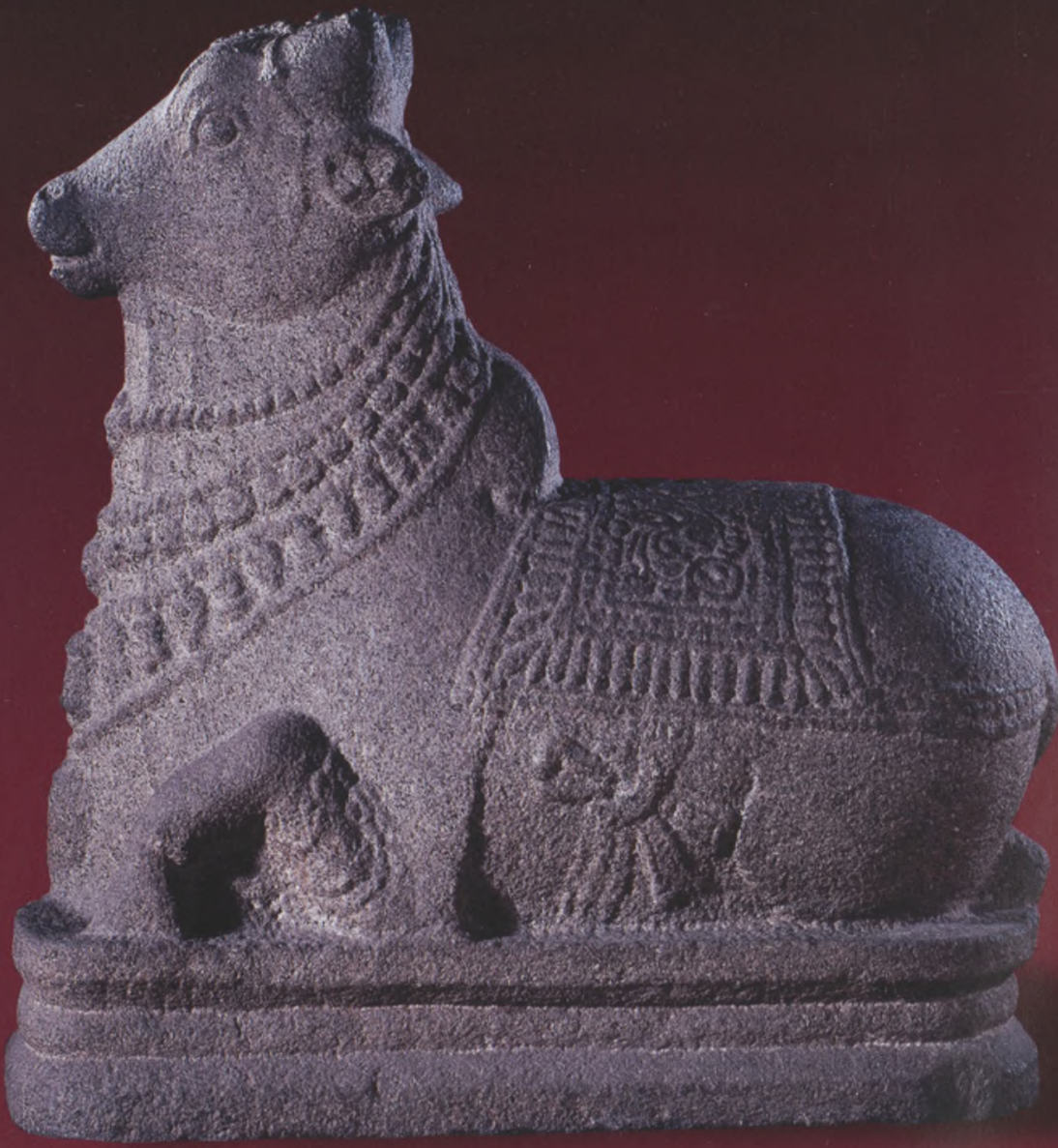

\section{Afbeelding 2}

Liggende stier, zand-

steen

h. $64,0 \mathrm{~cm}$.

India, Tamil Nadu,

$11^{e}$ eeuw

Rijksmuseum, legaat

C.J. Verburgt, inv.nr. 
De vrij grofkorrelige zandsteen waaruit het dier gehouwen is, werd veel gebruikt in Zuid-India. Het beeld is $64 \mathrm{~cm}$. hoog en $63 \mathrm{~cm}$. lang. Gezien het formaat, het materiaal en de houding behoort hij tot de rijdieren die in een tempelcomplex thuishoren.

Er is hier sprake van een speciaal type stier, dat in de bloeiperiode van de Chola (ca. $9^{\mathrm{e}}$ tot $13^{\mathrm{e}}$ eeuw) in Tamil Nadu gangbaar was. Kenmerkend zijn de relatief korte snuit met het hoge voorhoofd en de zware kaak, de kleine bult en de ongeplooide halskwabben. Stieren uit andere gebieden hebben wel dezelfde houding, maar hun kop is platter en ze hebben een langere snuit. $\mathrm{Ze}$ werden niet alleen uit steen gehakt, maar ook in brons gegoten.

De Chola of Cola (uitspraak Tsjola) woonden in zuidoost India in de streek tegenover Sri Lanka (Ceylon). Zij worden reeds genoemd in een rotsinscriptie van keizer Asoka in het midden van de derde eeuw voor onze jaartelling. Ze speelden een rol in de politieke, godsdienstige en culturele ontwikkeling van het gebied. Hun grootste macht en rijkdom hadden ze van de elfde tot de dertiende eeuw; in die tijd werden onder andere grote tempels gebouwd. De mannelijke leden van de Cola dynastie waren aanbidders van Shiva, zodat met name aan deze god in zijn verschillende verschijningen vele tempels gewijd zijn.

De Cola waren zeevaarders en handelslieden. Wat later bekend is bij zeevaarders als de Coromandelkust, is een verbasterde naam van het gebied van de Cola's, de Colamandala. Zij droegen er mede toe bij dat de cultuur en godsdienst van India in het Verre Oosten verspreid werd. Door hen en door andere stammen, die wat noordelijker langs die kust woonden, werden eerst het Boeddhisme en daarna het Hindoeisme in Indonesië geïntroduceerd. Dit laatste vooral in de Shivaitische vorm. Zo kunnen wij voor een van de bekendste Hindoetempels van Indonesië, de Shivatempel de Candi Loro Jonggrang in het Prambanan complex bij Yogyakarta op dezelfde wijze als in zuid-India een paviljoentje met de stier vinden.

\section{Noot}

1. Zie ook het artikel van Pauline Lunsingh Scheurleer, 'De stier van Shiva uit het legaat Verburgt', in: Aziatische Kunst 20/4 (1990), pp. 4-7. 